\title{
OA07-02. Adenovirus vectors induce expansion of memory CD4 T cells with a mucosal homing phenotype that are readily susceptible to HIV-I infection
}

\author{
A Benlahrech*1, J Harris², A Meiser ${ }^{1}$, T Papagatsias ${ }^{1}$, J Hornig1, P Hayes ${ }^{1}$, \\ A Lieber ${ }^{3}$, T Athanasopoulos ${ }^{2}$, V Bachy ${ }^{4}$, R Daniels ${ }^{5}$, K Fisher ${ }^{6}$, F Gotch ${ }^{1}$, \\ L Klavinskis ${ }^{4}$, L Seymour ${ }^{6}$, K Logan ${ }^{1}$, R Barbagallo ${ }^{1}$, G Dickson ${ }^{2}$ and \\ S Patterson ${ }^{1}$
}

Address: ${ }^{1}$ Immunology, Imperial College, London, UK, ${ }^{2}$ Royal Holloway University of London, Surrey, UK, ${ }^{3}$ University of Washington, Seattle, WA, USA, ${ }^{4}$ King's College London, London, UK, ${ }^{5}$ ational Institute for Medical Research, London, UK and ${ }^{6} \mathrm{Hybrid}$ Systems Ltd., Oxford, UK

* Corresponding author

from AIDS Vaccine 2009

Paris, France. 19 - 22 October 2009

Published: 22 October 2009

Retrovirology 2009, 6(Suppl 3):O50 doi:10.1 186/1742-4690-6-S3-O50

This abstract is available from: http://www.retrovirology.com/content/6/S3/O50

(C) 2009 Benlahrech et al; licensee BioMed Central Ltd.

\section{Background}

In the recently halted human immunodeficiency virus type 1 (HIV-1) vaccine STEP trial individuals that were seropositive for adenovirus serotype 5 (Ad5) showed increased rates of HIV-1 infection on vaccination with an Ad5 vaccine. We undertook a series of ex vivo strategies to address the hypothesis that immunisation of Ad5 seropositive individuals with adenoviral vectors may result in activation, expansion, and trafficking of Ad5-specific memory CD4 T cells to mucosal tissues thereby increasing the number of HIV-1 susceptible targets at the initial sites of infection.

\section{Methods}

Ad5 and Ad11 antibody titers were measured in 20 healthy volunteers. Dendritic cells (DC) were generated from these individuals, pulsed with replication defective Ad5 or Ad11 and co-cultured with autologous lymphocytes. Cytokine profiles, proliferative capacity and the migration potential of the adenovirus-stimulated memory $\mathrm{T}$ cells were measured. The susceptibility of re-stimulated memory Ad-specific T cells to infection with a CCR5-utilising HIV-1 was also assessed by multi-colour flow cytometric analysis and p24 ELISA assays.

\section{Results}

Stimulation of T cells from Ad5 seropositive but Ad11 seronegative individuals with Ad5, or serologically distinct Ad11 vectors induced expansion of adenovirus memory CD4 T cells expressing alpha 4 beta 7 and CCR9, indicating a mucosal-homing phenotype. CD4 T cell proliferation and IFN-gamma production in response to Ad stimulation correlated with Ad5 antibody titers. In contrast, Ad5 serostatus did not correlate with total cytokine production upon re-challenge with Ad5 or Ad11. Expanded Ad5 and Ad11 memory CD4 T cells showed an increase in CCR5 expression and higher susceptibility to infection by R5 tropic HIV-1.

\section{Conclusion}

Adenoviral-based vaccination against HIV-1 in individuals with pre-existing immunity against Ad5 may result in preferential expansion of HIV-susceptible activated CD4 T cells that home to mucosal tissues, increase the number of virus targets and lead to a higher susceptibility to HIV infection. 